\title{
New Potent Membrane-Targeting Antibacterial Peptides from Viral Capsid Proteins
}

\author{
Susana A. Dias' ${ }^{1}$, João M. Freire ${ }^{1,2}$, Clara Pérez-Peinado ${ }^{3}$, Marco M. Domingues $^{1}$, \\ Diana Gaspar ${ }^{1}$, Nuno Vale ${ }^{4}$, Paula Gomes ${ }^{5}$, David Andreu ${ }^{3}$, Sónia T. Henriques 6 , \\ Miguel A. R. B. Castanho ${ }^{1}$ and Ana S. Veiga ${ }^{1 *}$
}

\begin{abstract}
1 Instituto de Medicina Molecular, Faculdade de Medicina, Universidade de Lisboa, Lisbon, Portugal, ${ }^{2}$ Department of Virology, Institut Pasteur, Paris, France, ${ }^{3}$ Department of Experimental and Health Sciences, Pompeu Fabra University, Barcelona Biomedical Research Park, Barcelona, Spain, ${ }^{4}$ UCIBIO-REQUIMTE, Faculdade de Farmácia, Universidade do Porto, Porto, Portugal, ${ }^{5}$ LAQV-REQUIMTE, Departamento de Química e Bioquímica, Faculdade de Ciências, Universidade do Porto, Porto, Portugal, ${ }^{6}$ Institute for Molecular Bioscience, The University of Queensland, Brisbane, QLD, Australia
\end{abstract}

\section{OPEN ACCESS}

Edited by:

Luis Cláudio Nascimento da Silva, CEUMA University, Brazil

Reviewed by: Osmar Nascimento Silva, Universidade Católica Dom Bosco,

Brazil

Alessandra Romanelli, University of Naples Federico II, Italy

*Correspondence: Ana S. Veiga aveiga@medicina.ulisboa.pt

Specialty section: This article was submitted to Antimicrobials, Resistance and Chemotherapy,

a section of the journal

Frontiers in Microbiology

Received: 28 February 2017

Accepted: 18 April 2017

Published: 04 May 2017

Citation:

Dias SA, Freire JM, Pérez-Peinado C, Domingues MM Gaspar D, Vale N, Gomes P, Andreu D, Henriques ST, Castanho MARB and Veiga AS (2017) New Potent Membrane-Targeting Antibacterial Peptides from Viral Capsid Proteins.

Front. Microbiol. 8:775. doi: 10.3389/fmicb.2017.00775
The increasing prevalence of multidrug-resistant bacteria urges the development of new antibacterial agents. With a broad spectrum activity, antimicrobial peptides have been considered potential antibacterial drug leads. Using bioinformatic tools we have previously shown that viral structural proteins are a rich source for new bioactive peptide sequences, namely antimicrobial and cell-penetrating peptides. Here, we test the efficacy and mechanism of action of the most promising peptides among those previously identified against both Gram-positive and Gram-negative bacteria. Two cell-penetrating peptides, vCPP 0769 and vCPP 2319, have high antibacterial activity against Staphylococcus aureus, MRSA, Escherichia coli, and Pseudomonas aeruginosa, being thus multifunctional. The antibacterial mechanism of action of the two most active viral protein-derived peptides, vAMP 059 and VCPP 2319, was studied in detail. Both peptides act on both Gram-positive S. aureus and Gram-negative $P$. aeruginosa, with bacterial cell death occurring within minutes. Also, these peptides cause bacterial membrane permeabilization and damage of the bacterial envelope of $P$. aeruginosa cells. Overall, the results show that structural viral proteins are an abundant source for membrane-active peptides sequences with strong antibacterial properties.

Keywords: antimicrobial peptides (AMPs), cell-penetrating peptides (CPPs), minimum inhibitory concentration (MIC), minimal bactericidal concentration (MBC), membrane permeabilization, atomic force microscopy (AFM)

\section{INTRODUCTION}

Bacterial resistance to conventional antibiotics has increased drastically during the last decades, making difficult the effective treatment of infections caused by drug-resistant bacteria (Tanwar et al., 2014; Brown, 2015). According to a recent report from the World Health Organization (WHO, 2014), it is estimated that each year, in the European Union alone, over two million people become infected with resistant bacteria, of which 25,000 die. Also, it has been described that methicillin-resistant Staphylococcus aureus kills more Americans each year than HIV, Parkinson's disease, emphysema, and homicide combined (Ventola, 2015). This represents a real threat to human health worldwide and has driven the search for novel effective antibacterial agents. 
Antimicrobial peptides (AMPs) have emerged as potential alternatives to currently used antibiotics (Zasloff, 2002; Baltzer and Brown, 2011). This group of molecules can be found in all life forms, from microorganisms to plants and animals, and are known to have broad spectrum activity against multiple microorganisms, including bacteria, fungi, viruses and parasites (Zasloff, 2002; Jenssen et al., 2006; Nguyen et al., 2011). AMPs are very diverse in their amino acid sequences and folding (Hancock, 2001; Powers and Hancock, 2003; Peters et al., 2010), and display mechanisms of action that are distinct from the ones used by conventional antibiotics (Sancho-Vaello and Zeth, 2015). It has been proposed that the first step in their action involves the contact with bacterial membranes, which occurs through electrostatic and hydrophobic interactions with negatively charged lipids on the cell membrane (Yeaman and Yount, 2003; Teixeira et al., 2012). Membrane-targeting is usually followed by permeabilization and disruption of the lipid bilayer structure, leading to loss of integrity and ultimately cell death (Shai, 2002). Alternatively, some AMPs can exert their antimicrobial activity by targeting intracellular metabolic processes without damaging membrane integrity (Park et al., 2000; Brogden, 2005; Bahar and Ren, 2013). Currently, some AMPs are already clinically available, such as the cationic lipopeptide polymyxin B (Sandri et al., 2013) and the cyclic cationic peptide gramicidin S (Mogi and Kita, 2009), and many are in clinical development (Mahlapuu et al., 2016).

Peptide sequences with antimicrobial properties have been identified using different approaches, such as, identification of bioactive compounds on natural extracts (Bulet et al., 2004), in silico analysis of natural proteins (Torrent et al., 2012), de novo or structure-based design, or chimeras of peptide fragments (Piers et al., 1994; Wu and Hancock, 1999; Rozek et al., 2003; Brogden and Brogden, 2011). Since enveloped viruses are abundant in multifunctional proteins, using bioinformatic tools we searched structural viral proteins for bioactive peptides sequences (Freire et al., 2015a), namely AMPs and cell-penetrating peptides (CPPs). CPPs are a group of peptides capable of crossing biological membranes without causing significant membrane damage (Gräslund et al., 2011). Given the similarities in the structure and activity between these two groups of peptides, it has been proposed that CPPs are not totally distinct from AMPs (Henriques et al., 2006; Zhu et al., 2006; Splith and Neundorf, 2011).

In this study, we intended to investigate the antibacterial activity and mechanism of action of previously identified viral protein-derived peptides (Table 1) (Freire et al., 2015a). First, the potential antibacterial activity of six selected viral protein-derived peptides proven to have cell-penetrating properties (vCPPs) was evaluated against Gram-positive and Gram-negative bacteria. The results obtained allowed to identify two vCPPs with high antibacterial activity, vCPP 0769 and vCPP 2319, showing that viral protein-derived sequences are a possible source for peptides with dual action. Furthermore, the antibacterial mechanism of action of the two most active viral protein-derived peptide sequences, vAMP 059, previously identified (Freire et al., 2015a), and vCPP 2319, was investigated and the results show that the peptides act mainly through a mechanism involving membrane disruption. This study shows the potential of viral structural proteins as a source of bioactive peptides sequences with antibacterial properties.

\section{MATERIALS AND METHODS}

\section{Peptide Selection and Synthesis}

Peptide selection was performed based on a previous study (Freire et al., 2015a) in which viral proteins were searched for AMPs and CPPs using AMPA and CellPPD bioinformatic tools, respectively. The AMPA server (Torrent et al., 2012) is based on an antimicrobial propensity scale that considers the physical chemical properties of each amino acid, such as hydrophobicity and amphipathicity, and the relevance of amino acid position for antimicrobial activity. An antimicrobial index (AI) $<0.225$ was considered a positive hit for an AMP. CellPPD is a Support Vector Machine (SVM) that scores each amino acid residue sequence with a SVM score (Gautam et al., 2013). A SVM > 0 was considered a positive CPP hit. Several peptide sequences were selected for experimental validation, based on their sequence novelty (when compared to the AMP/CPP sequences listed on the existing databases) and best ranking in AI and SVM score. The selection covered a broad range of scores and peptide sequence physical-chemical properties such as hydrophobicity and amphipathicity. The most active peptides were selected for the present study.

All the peptides have an amidated C-terminus and a free amine N-terminus. The viral protein-derived CPPs (vCPPs) used in this study, Table 1, were synthesized by Bachem AG (Bubendorf, Switzerland) with a purity of $>95 \%$. The viral protein-derived AMP used, vAMP 059 (Table 1), was synthesized on a standard Fmoc-Rink amide MBHA resin, using a Liberty 1 Microwave Peptide Synthesizer (CEM Corporation, Mathews, NC, USA). Standard Fmoc/tBu SPPS protocols were applied following procedures previously reported by us (Monteiro et al., 2015; Barbosa et al., 2017). The crude peptide was purified by preparative HPLC to a final $100 \%$ purity, as evaluated by analytical HPLC. The pure peptide was analyzed by electrospray-ionization/ion-trap mass spectrometry (ESI-IT MS). The average calculated mass and observed mass values of all vCPPs and vAMP 059 are shown in Supplementary Table S1.

To prepare stock solutions lyophilized peptides were weighed out on a high precision analytical microbalance $(0.01 \mathrm{mg} \pm 0.02)$, dissolved in sterile Milli-Q water and stored at $-20^{\circ} \mathrm{C}$.

\section{Antibacterial Activity Assay}

The antibacterial activity of the vCPPs was tested using a standard broth microdilution procedure (Wikler et al., 2006; Wiegand et al., 2008) to evaluate the bacterial growth inhibition and determine the minimal inhibitory concentration (MIC). The assay was performed using the following strains: Gram-positive Staphylococcus aureus (S. aureus) ATCC 25923 and methicillin-resistant Staphylococcus aureus (MRSA) ATCC 33591, and Gram-negative Escherichia coli (E. coli) ATCC 25922 and Pseudomonas aeruginosa ( $P$. aeruginosa) ATCC 27853, obtained from American Type Culture Collection (ATCC) 
TABLE 1 | Viral protein-derived peptides used in this study.

\begin{tabular}{|c|c|c|c|c|}
\hline Name & Sequence & Length & Net charge & Source (protein:position) \\
\hline vCPP 0275 & KKRYKKKYKAYKPYKKKKKKF-NH ${ }_{2}$ & 20 & +14 & Cauliflower mosaic virus (Capsid: aa367-387) \\
\hline vCPP 0417 & SPRRRTPSPRRRRSQSPRRR-NH $\mathrm{N}_{2}$ & 20 & +11 & Hepatitis B virus genotype C (Capsid: aa155-175) \\
\hline vCPP 0667 & RPRRRATTRRRITTGTRRRR-NH 2 & 20 & +12 & Human Adenovirus C serotype 1 (Minor Core Protein - Capsid: aa314-334) \\
\hline vCPP 0769 & RRLTLRQLLGLGSRRRRRSR-NH $\mathrm{N}_{2}$ & 20 & +10 & Fowl adenovirus A serotype 1 (Major Capsid Protein: aa17-37) \\
\hline vCPP 1779 & GRRGPRRANQNGTRRRRRRT-NH ${ }_{2}$ & 20 & +11 & Barley Virus (Capsid: aa5-25) \\
\hline vCPP 2319 & WRRRYRRWRRRRRWRRRPRR-NH $\mathrm{H}_{2}$ & 20 & +16 & Torque teno douroucouli vírus (Capsid: aa16-36) \\
\hline VAMP 059 & INWKKWWQVFYTW-NH 2 & 14 & +3 & Rotavirus VP7 (Capsid: aa94-107) \\
\hline
\end{tabular}

(Manassas, VA, USA). Bacterial suspensions were prepared by direct suspension of morphologically similar colonies on Mueller Hinton Broth (MHB) from BD (Franklin Lakes, NJ, USA) to a final concentration of $1 \times 10^{6} \mathrm{CFU} / \mathrm{mL}$, and added to a sterile 96-well microtiter polypropylene plate from Corning (Corning, NY, USA) containing two-fold dilutions of each peptide. Final bacterial concentration was $5 \times 10^{5}$ $\mathrm{CFU} / \mathrm{mL}$ whereas peptide concentrations ranged between 100 and $0.78 \mu \mathrm{M}$. The 96 -well plate was incubated at $37^{\circ} \mathrm{C}$ for $18 \mathrm{~h}$. The MIC was defined as the lowest peptide concentration required to inhibited visible bacterial growth. The assay was performed in triplicate.

\section{Bactericidal Activity Assay}

To study the bactericidal activity of the most active viral protein-derived peptides, the minimal bactericidal concentration (MBC) was determined by a colony count assay (Barry et al., 1999). After the MIC assay, aliquots were removed from the wells with no visible bacterial growth, serially diluted in $\mathrm{MHB}$, plated on nutrient-rich trypcase soy agar (TSA) plates from bioMérieux (Marcy l'Etoile, France), and incubated at $37^{\circ} \mathrm{C}$ for $24 \mathrm{~h}$. After incubation, bacterial colonies were counted and the $\mathrm{MBC}$ was defined as the lowest peptide concentration that caused $\geq 99.9 \%$ cell death of the initial bacterial inoculum. The assay was performed in triplicate.

\section{Time-Kill Assay}

For viral protein-derived peptides displaying bactericidal activity, bacterial killing kinetics was determined by a conventional method based on colony counts obtained after different times of exposure of the bacterial cells to the peptides (Barry et al., 1999). The assay was performed using $S$. aureus and $P$. aeruginosa as representative strains of Gram-positive and Gram-negative bacteria, respectively. Bacterial suspensions prepared in $\mathrm{MHB}$ at $5 \times 10^{5} \mathrm{CFU} / \mathrm{mL}$ were treated with each peptide at final concentrations corresponding to their $\mathrm{MBC}$, and incubated at $37^{\circ} \mathrm{C}$ and $200 \mathrm{rpm}$. A control of bacterial suspensions without peptide was performed under the same conditions. Aliquots of untreated and peptide-treated bacterial suspensions were withdrawn at $0,15,30,60,120$, and $180 \mathrm{~min}$, serially diluted in $\mathrm{MHB}$, and plated on TSA plates. Bacterial colonies were counted after $24 \mathrm{~h}$ of incubation at $37^{\circ} \mathrm{C}$. Viable bacteria (in CFU/mL) are reported as percentage of the control. The assay was performed in triplicate.

\section{SYTOX Green Uptake Assay}

SYTOX $^{\circledR}$ Green (Invitrogen, Carlsbad, CA, USA) is a high-affinity nucleic acid stain that only penetrates cells with compromised plasma membranes and emits fluorescence when bound to DNA (Roth et al., 1997). A SYTOX Green uptake assay (Torcato et al., 2013; Sani et al., 2015) was performed using $P$. aeruginosa to study the effect of viral protein-derived peptides on those bacterial membranes. Bacterial suspensions at $1 \times 10^{8} \mathrm{CFU} / \mathrm{mL}$ in $\mathrm{MHB}$ were centrifuged for $10 \mathrm{~min}$ at $4000 \times g$ and the pellet resuspended in $10 \mathrm{mM}$ HEPES buffer, $\mathrm{pH}$ 7.4 , containing $150 \mathrm{mM} \mathrm{NaCl}$, to a final concentration of $5 \times 10^{5}$ $\mathrm{CFU} / \mathrm{mL}$. The bacterial suspensions were incubated for $1 \mathrm{~h}$ at $37^{\circ} \mathrm{C}$ and $200 \mathrm{rpm}$, with twofold dilutions of each bactericidal viral protein-derived peptide in a range of concentrations starting at their corresponding MBC. Peptide-treated bacterial cells were incubated with $0.1 \mu \mathrm{M}$ of SYTOX Green for $10 \mathrm{~min}$, on ice and protected from light. The fluorescence emission intensity signal was measured by flow cytometry (excitation with $488 \mathrm{~nm}$ laser and detection at $530 \mathrm{~nm}$ with $30 \mathrm{~nm}$ bandpass) and a total of 50000 events were recorded. Flow cytometry experiments were performed using a BD LSR Fortessa from BD Biosciences (San Jose, CA, USA). The percentage of permeabilized cells was determined considering that untreated bacterial cells (negative control) are $0 \%$ permeabilized and bacterial cells treated with isopropyl alcohol (positive control) are 100\% permeabilized. To study the correlation between bacterial cell permeabilization and viability, a viability assay using a colony count method was used. Using the same conditions described for the SYTOX Green uptake assay, untreated and peptide-treated bacterial suspensions were incubated, aliquots were serially diluted in HEPES buffer, and plated on TSA plates. Plates were incubated at $37^{\circ} \mathrm{C}$ for $24 \mathrm{~h}$. From the number of bacterial colonies obtained, viable bacteria (in $\mathrm{CFU} / \mathrm{mL}$ ) are reported as percentage of the control. The assays were performed in triplicate.

\section{Atomic Force Microscopy (AFM) Imaging}

Atomic force microscopy (AFM) imaging was used to study the effect of the bactericidal viral protein-derived peptides on $P$. aeruginosa cells. Bacterial suspensions at $1 \times 10^{8} \mathrm{CFU} / \mathrm{mL}$ in $\mathrm{MHB}$ were centrifuged for $10 \mathrm{~min}$ at $4000 \times \mathrm{g}$, and the pellet resuspended in HEPES buffer to a final concentration of $1 \times 10^{7} \mathrm{CFU} / \mathrm{mL}$. The bacterial suspensions were treated with each peptide at concentrations corresponding to their $\mathrm{MBC}$, as well as the concentrations above and below their MBC, and incubated for $1 \mathrm{~h}$ at $37^{\circ} \mathrm{C}$ and $200 \mathrm{rpm}$. As control, 
untreated bacterial suspension was also incubated using the same conditions. A $200 \mu \mathrm{L}$ droplet of each test sample was applied on a poly-L-lysine-coated glass slide and allowed to deposit for $20 \mathrm{~min}$ at room temperature. Each sample was then rinsed 10 times with sterile Milli-Q water and allowed to dry for $30 \mathrm{~min}$ at room temperature. AFM images were acquired using a JPK NanoWizard II (Berlin, Germany) mounted on a Zeiss Axiovert 200 inverted microscope (Göttingen, Germany). Measurements were carried out in air and in intermittent contact mode using uncoated silicon ACL cantilevers from APPNano (Mountain View, CA, USA). ACL cantilevers had typical resonance frequencies of $190 \mathrm{kHz}$ and a spring constant of $45 \mathrm{~N} / \mathrm{m}$. Bacteria were first visualized through the optical microscope before being selected for imaging. On average, 14 untreated bacteria and 10 individual bacterial cells were imaged for each peptide concentration, with a total area of $4 \mu \mathrm{m} \times 4 \mu \mathrm{m}$ from three independent bacterial preparation slides. Height images were recorded and treated with JPK SPM data processing 5.1.8.

\section{RESULTS}

\section{Antibacterial Activity of vCPPs}

The antibacterial activity of six viral protein-derived CPPs (vCPPs; Table 1) was evaluated by determining the MIC against $S$. aureus and MRSA, and E. coli and P. aeruginosa, as representative models of Gram-positive and Gram-negative bacteria, respectively. The MIC values obtained for each peptide are presented in Table 2. Among the vCPPs studied, two peptides, vCPP 0769 and vCPP 2319, exhibited high antibacterial activity against all bacterial strains tested. vCPP 0769 was particularly active against $S$. aureus, MRSA and $P$. aeruginosa, with a MIC of $3.13 \mu \mathrm{M}$ for these three bacteria, whereas for $E$. coli a MIC value of $25 \mu \mathrm{M}$ was obtained. vCPP 2319 displayed high antibacterial activity against all bacterial strains tested, with a MIC of $1.56 \mu \mathrm{M}$ for S. aureus and MRSA, and $3.13 \mu \mathrm{M}$ for $E$. coli and $P$. aeruginosa.

\section{Bactericidal Activity of Viral Protein-Derived Peptides}

To assess whether vCPP 0769 and vCPP 2319 are bactericidal or bacteriostatic, their MBC was determined for all bacterial strains tested. Peptides are considered bacteriostatic if their

TABLE 2 | Antibacterial activity of vCPPs.

\begin{tabular}{lcccc}
\hline Peptide & \multicolumn{4}{c}{ MIC $(\boldsymbol{\mu} \mathbf{M})$} \\
\cline { 2 - 5 } & S. aureus & MRSA & E. coli & P. aeruginosa \\
\hline VCPP 0275 & $25-50$ & 50 & 12.5 & 100 \\
VCPP 0417 & $>100$ & $>100$ & 25 & 100 \\
vCPP 0667 & 50 & 100 & 12.5 & 25 \\
VCPP 0769 & 3.13 & 3.13 & 25 & 3.13 \\
VCPP 1779 & $100->100$ & $>100$ & 25 & 25 \\
VCPP 2319 & 1.56 & 1.56 & 3.13 & 3.13
\end{tabular}

MBC is more than fourfold their MIC, and bactericidal when their MBC is equal or lower than four-fold their MIC (Levison and Levison, 2009). The MBC values obtained are presented in Table 3. vCPP 2319 exhibited bactericidal activity against all bacterial strains tested. On the other hand, vCPP 0769 showed to be bactericidal only against E. coli and P. aeruginosa, whereas for S. aureus and MRSA it only inhibited bacterial growth. Additionally, the bactericidal activity of the peptide vAMP 059 was also studied. This peptide was identified in our previous screen for antimicrobial sequences from structural viral proteins showing high antibacterial activity against $S$. aureus and $P$. aeruginosa, with MIC values of 0.78 and $6.25 \mu \mathrm{M}$, respectively (Freire et al., 2015a). MBC values showed the peptide is bactericidal against both $S$. aureus and $P$. aeruginosa strains tested.

\section{Bactericidal Kinetics of Viral Protein-Derived Peptides}

The above-mentioned results show that vAMP 059 and vCPP 2319 are the most active peptides with a broad bactericidal activity against the Gram-positive and Gram-negative bacterial strains tested. Bacterial killing kinetics of $S$. aureus and $P$. aeruginosa by vAMP 059 and vCPP 2319 were determined at the MBC (Figure 1). In the presence of both peptides, a significant reduction in the number of viable bacteria occurred within minutes, although a faster bacterial killing was observed for $S$. aureus (Figure 1A) when compared to $P$. aeruginosa (Figure 1B). Both vAMP 059 and vCPP 2319 exhibited a fast bactericidal activity against $S$. aureus with a reduction in bacterial viability of 99.9 and $90.9 \%$, respectively, after 30 min of peptide activity. Both peptides exhibited a slower bactericidal activity against $P$. aeruginosa. In this case, cell viability decreased more gradually over time with a 99.7 and $97 \%$ reduction of bacterial viability occurring after $180 \mathrm{~min}$ of exposure to vAMP 059 and vCPP 2319, respectively.

\section{Viral Protein-Derived Peptides Induce Permeabilization of $P$. aeruginosa Cells}

A fast bacterial killing kinetics is frequently observed for AMPs and is related to their membrane-disrupting mode of action. To investigate if peptides vAMP 059 and vCPP 2319 affect bacterial membrane integrity, $P$. aeruginosa permeability to the SYTOX Green dye was studied after treatment with increasing peptide concentrations, with an increase in the dye fluorescence intensity directly reflecting membrane permeabilization (Roth et al., 1997). Results (Figure 2) showed an increase in membrane

TABLE 3 | Bactericidal activity of vCPP 0769, vCPP 2319, and vAMP 059.

\begin{tabular}{lcccc}
\hline Peptide & \multicolumn{4}{c}{ MBC $(\boldsymbol{\mu M})$} \\
\cline { 2 - 5 } & S. aureus & MRSA & E. coli & $\boldsymbol{P}$. aeruginosa \\
\hline VCPP 0769 & $>100$ & $>100$ & 50 & 6.25 \\
VCPP 2319 & 3.13 & 3.13 & 3.13 & 3.13 \\
VAMP 059 & 1.56 & - & - & 6.25
\end{tabular}


A

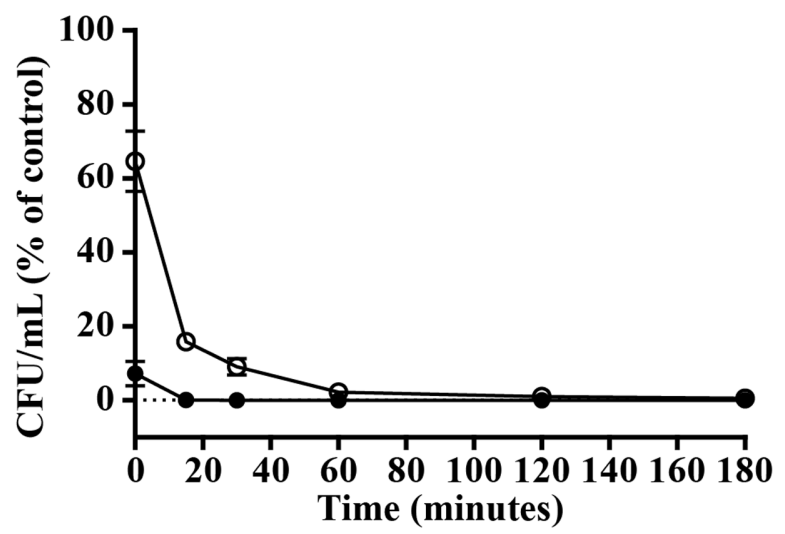

B

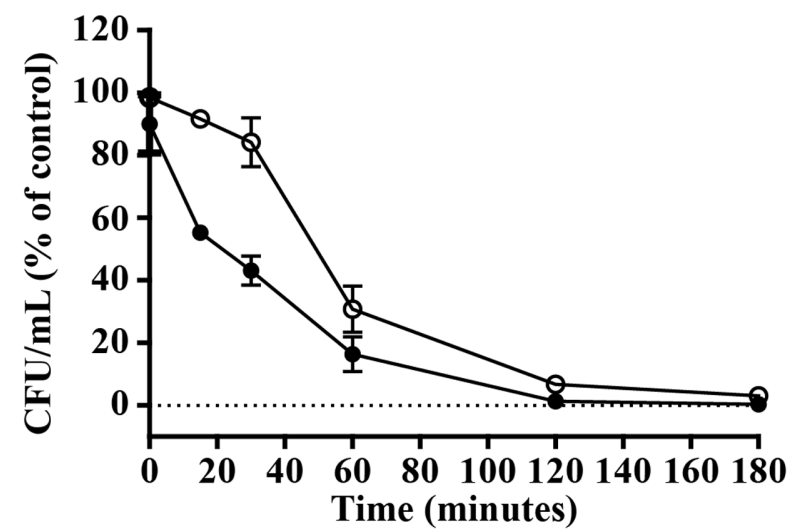

FIGURE 1 | Killing kinetics of S. aureus (A) and P. aeruginosa (B). Bacterial cells were exposed to the peptides vAMP 059 ( $)$ and vCPP 2319 (o) at their MBC. Viable bacteria (in CFU/mL) are reported as percentage of the control without peptide. Data correspond to mean \pm SD of three independent experiments.

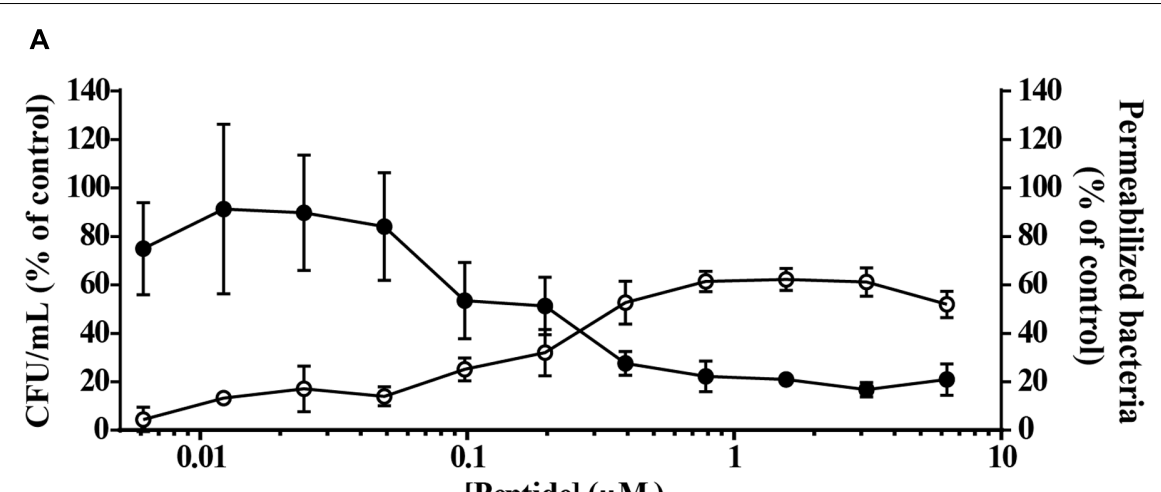

B

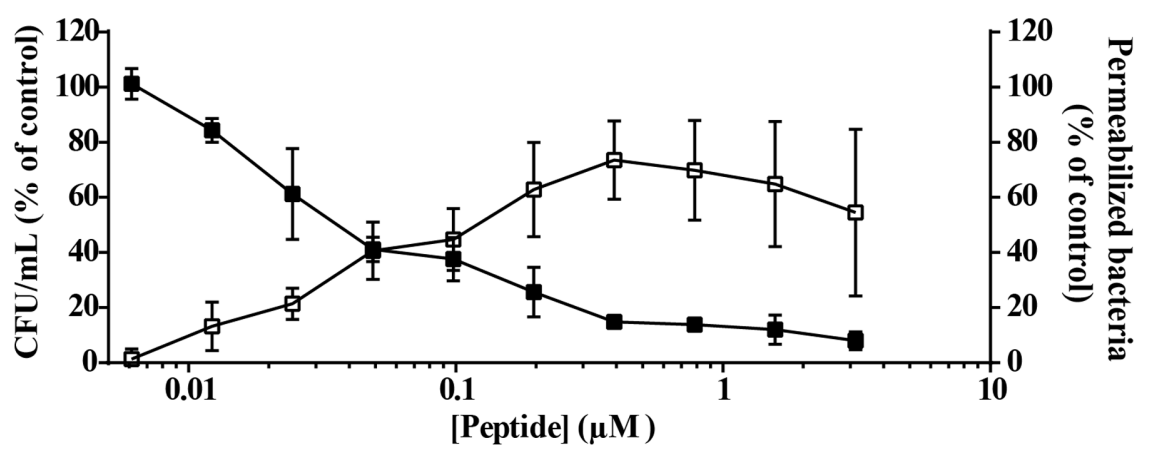

FIGURE 2 | Bacterial cells viability and membrane permeabilization after treatment with vAMP 059 (A) or vCPP 2319 (B). P. aeruginosa cells were incubated with a range of concentrations of vAMP 059 or vCPP 2319 for $1 \mathrm{~h}$ at $37^{\circ} \mathrm{C}$. Viable bacteria (in CFU/mL) ( $\left.\mathbf{\square}\right)$ and permeabilized bacteria ( $\left.\bigcirc, \square\right)$ are reported as a percentage of the control. Data correspond to mean $\pm \mathrm{SD}$ of three independent experiments.

permeabilization with increasing peptide concentrations. However, it was also noticed that at high concentrations of both peptides there was a slight reduction in permeabilization. Such result may be due to SYTOX Green displacement from nucleic acids by the peptides, which would cause a reduction in its fluorescence emission intensity and consequently an apparent reduction in the percentage of permeabilized bacteria.

Simultaneously with the SYTOX Green uptake assay, a viability assay was performed for both peptides under the same conditions. Results demonstrated a correlation between $P$. aeruginosa permeability and viability in the presence of vAMP 
059 (Figure 2A) and vCPP 2319 (Figure 2B). These results show that both peptides kill bacteria through membrane-disruption mechanisms.

\section{Bioimaging of the Viral Protein-Derived Peptides Effect on $P$. aeruginosa Cells}

Atomic force microscopy imaging was used to visualize the morphological changes in $P$. aeruginosa after treatment with vAMP 059 and vCPP 2319. The images obtained in air for untreated $P$. aeruginosa cells (Figure 3A) showed, in all cases, the characteristic rod shaped structure as well as a corrugated surface with no visible pores or ruptures. Treatment of bacteria with increasing concentrations of both peptides revealed a clear effect on cell envelope integrity when compared with untreated bacteria, although the cells maintained their global rod-like form. After treatment with vAMP 059, a pronounced collapse in $P$. aeruginosa cell envelope occurred at all concentrations tested (Figures 3B-D). For vCPP 2319 a similar result was observed, but a more gradual effect with increasing concentrations of peptide was observed (Figures 3E-G). At $1.56 \mu \mathrm{M}$, a concentration below $\mathrm{MBC}$, only minor alterations on bacterial topography were observed.

\section{DISCUSSION}

The therapeutic options for treatment of bacterial infections are drastically decreasing due to a fast increase in drug resistance. Driven by the need to discover new and effective antimicrobial agents, this work has focused on a group of promising alternatives, the AMPs.

In a previous study performed in our lab, we became aware that, among AMPs and CPPs derived from natural sources and listed on existing databases, only a few of them were related to viral proteins. Using bioinformatic tools, a set of peptide sequences with potential antimicrobial and cell-penetrating properties was identified, suggesting that viruses are an underexplored source for AMPs and CPPs (Freire et al., 2015a). One viral protein-derived AMP (vAMP 059) and ten viral protein-derived CPPs (vCPPs) were identified. In this study, from the six more active $\mathrm{vCPPs}$, we were able to identify two peptides, vCPP 0769 and vCPP 2319, with concurrent, strong antibacterial activity. vCPP 2319 demonstrated to be active at low micromolar range concentrations, being bactericidal against all the bacterial strains tested. vCPP 0769 revealed high antibacterial activity against the $S$. aureus, MRSA and $P$. aeruginosa strains, and a moderate activity against $E$. coli, but only displayed bactericidal activity against the Gramnegative bacterial strains tested. Therefore, both peptides reveal a dual cell-penetrating and antibacterial activity, a peculiar cross functionality that has been reported for few other peptides (Takeshima et al., 2003; Nekhotiaeva et al., 2004; Bobone et al., 2011). It has been proposed that peptides with dual antimicrobial and cell-penetrating properties might constitute potential candidates to target intracellular pathogenic bacteria (Bahnsen et al., 2013; Torcato et al., 2013) that escape host defenses (Ernst et al., 1999) and are extremely difficult to treat with conventional antibiotics (Clement et al., 2005).

In the present study, the results also show that the previously identified viral protein-derived peptide vAMP 059, with demonstrated activity against $S$. aureus and $P$. aeruginosa (Freire et al., 2015a), revealed a bactericidal mode of action against these bacterial strains. It is interesting to notice that this peptide, as well as both vCPP 0769 and vCPP 2319, are derived from viral capsid proteins (Freire et al., 2015a). Despite the fact that only few viral-derived AMPs are known, there are other examples of peptides with antimicrobial properties derived from viral capsid proteins. HBc ARD, is a peptide derived from the capsid protein of the human hepatitis B virus (Chen et al., 2013), and pepR, derived from the putative RNA-binding domain of the dengue virus capsid protein (Alves et al., 2010). Viral capsid proteins are known as multifunctional proteins and some of them can also be described as super charged proteins, a class of proteins with high net charge to molecular mass ratio and are known to have cell-membrane translocating properties (Freire et al., 2015b). In fact, there are several examples of cell-penetrating domains found in capsid proteins. With Dengue virus capsid protein as an example, we showed that one of these domains, the aforementioned pepR, also displays antibacterial activity. This potential antibacterial activity of viral proteins may have conferred viruses an evolutionary advantage over bacteria (Freire et al., 2015b). Additionally, the presence of domains with both antibacterial and cell-penetrating properties in viral capsid proteins demonstrates the potential use of viral proteins in drug discovery.

To get insights on the mode of action of the viral protein-derived peptides, the most active peptides vAMP 059 and vCPP 2319 were studied. Both peptides revealed a fast killing kinetics against $S$. aureus and $P$. aeruginosa. Since it is known that antimicrobial agents that kill within minutes of bacterial exposure, at concentrations similar to their MICs, act by disrupting bacterial membranes (Zasloff, 2002; Melo et al., 2009), we can suggest that both viral protein-derived peptides induce bacterial death through membrane disruption. This behavior is common amongst AMPs; for instance, the antimicrobial peptide melittin, derived from bee venom, exhibits an extremely rapid membrane-disrupting action, killing bacteria within minutes (Kaplan et al., 2011). Additionally, when comparing vAMP 059 and vCPP 2319 killing kinetics on both bacterial strains tested here, faster rates were observed against $S$. aureus than against $P$. aeruginosa. This behavior can be related to the differential peptide affinity for the molecular structures on Gram-negative or Gram-positive bacteria envelope surfaces. Gram-positive bacteria envelope consists on a single lipid membrane followed by a thick peptidoglycan layer enriched in negatively charged teichoic acids (Xia et al., 2010). In contrast, Gram-negative bacteria possesses an inner cytoplasmic membrane surrounded by a thin peptidoglycan layer and an outer membrane containing negative lipopolysaccharides (LPS) (Beveridge, 1999). For instance, the peptide $\mathrm{rBPI}_{21}$ exerts its antimicrobial activity through interactions with LPS of the outer membrane of Gram-negative bacteria, followed by fusion of the bacterial outer and inner membranes (Domingues et al., 2009). In turn, the antimicrobial 
A

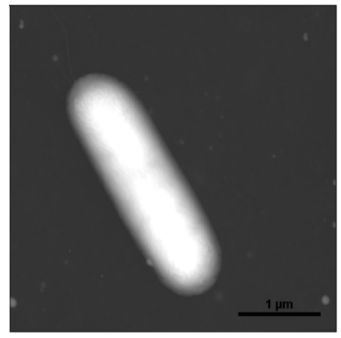

\section{Control}

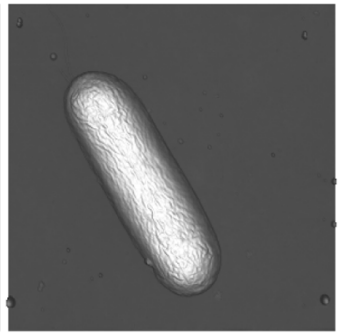

VAMP 059

B
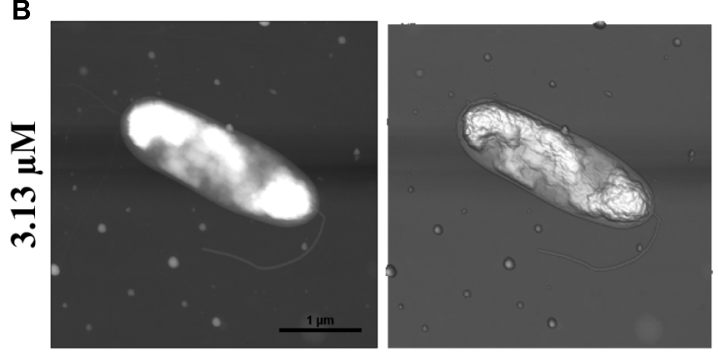

C
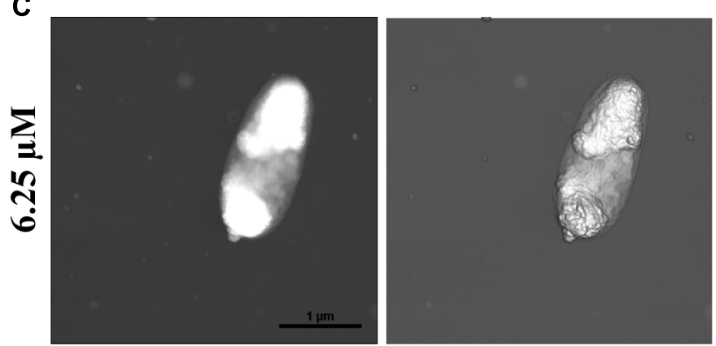

D
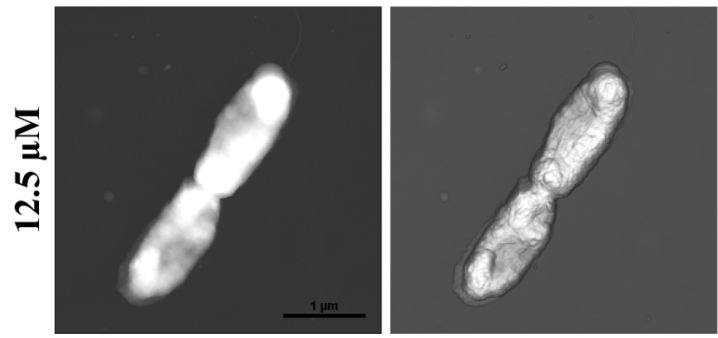

E

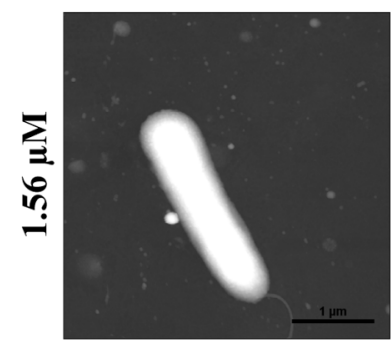

vCPP 2319

$\mathbf{F}$

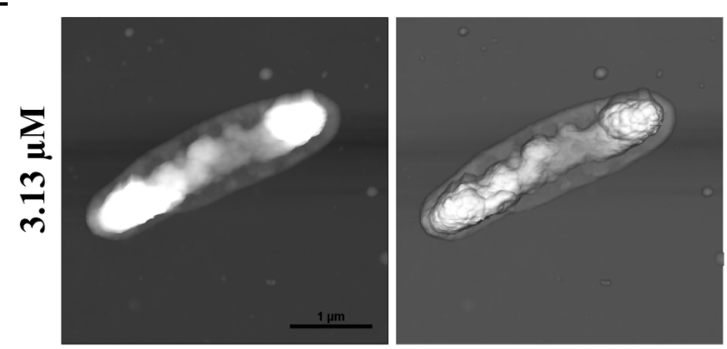

G

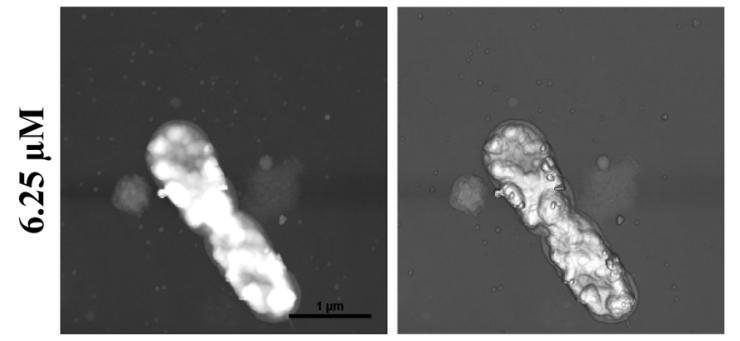

FIGURE 3 | Effect of vAMP 059 and vCPP 2319 on $\boldsymbol{P}$. aeruginosa cells imaged by AFM. (A) AFM height image (left image) and three-dimensional projection (right image) of $P$. aeruginosa cells incubated for $1 \mathrm{~h}$ in the absence of peptide (control). (B-G) AFM height images and three-dimensional projections of $P$. aeruginosa cells incubated for $1 \mathrm{~h}$ with increasing concentrations of vAMP 059 (B-D) and vCPP 2319 (E-G). Total scanning area for each image was $4 \mu \mathrm{m} \times 4 \mu \mathrm{m}$.

peptide omiganan has high affinity for the peptidoglycan layer in Gram-positive bacteria (Melo and Castanho, 2007). vAMP 059 and vCPP 2319 may have faster interaction with peptidoglycan when compared to LPS, resulting on a faster killing kinetics towards $S$. aureus rather than $P$. aeruginosa. The hypothesis that vAMP 059 and vCPP 2319 cause bacterial cell membrane disruption was confirmed in Gram-negative $P$. aeruginosa cells. Both peptides induce permeabilization of the outer and inner membranes, in a concentration-dependent manner, as shown using the non-permeable SYTOX Green dye, which was able to bind to the nucleic acids of bacterial cells treated with peptide. A mechanism involving membrane disruption was further confirmed by AFM imaging. Treatment of $P$. aeruginosa cells with VAMP 059 induced a pronounced collapse at the septal region of the cell envelope at all concentrations tested. Negatively charged cardiolipin domains are located at the apical and septal regions of E. coli cells (Mileykovskaya and Dowhan, 2000). Assuming a similar cardiolipin-distribution for $P$. aeruginosa, 
the observed collapse in the mid-region could be explained by accumulation of the peptides in these regions due to electrostatic attractions between the positively charged peptides and these negatively charged domains. Treatment of $P$. aeruginosa with vCPP 2319 at concentrations below the MBC did not cause substantial alterations on cell membrane morphology. However, treatment with $\mathrm{MBC}$, or higher, caused a marked collapse of the membrane structure. Overall, AFM imaging suggested that both peptides cause significant structural alterations on bacterial cell surface, which is in agreement with the proposed hypothesis that vAMP 059 and vCPP 2319 act at the membrane-level.

\section{AUTHOR CONTRIBUTIONS}

SD, CP-P, MD, DG, ST-H, MC, and ASV designed the experiments. SD, CP-P, MD, DG, and ASV performed the experimental work and data analysis. JF contributed with the design of the studied peptides. PG and NV contributed with peptide synthesis. All authors contributed to data interpretation and discussion. SD, MC, and ASV wrote the manuscript with contributions from all other authors.

\section{FUNDING}

This work was supported by Fundação para a Ciência e a Tecnologia (FCT-MCTES, Portugal) projects PTDC/QEQ$\mathrm{MED} / 4412 / 2014$ and UID/QUI/50006/2013, and by Marie

\section{REFERENCES}

Alves, C. S., Melo, M. N., Franquelim, H. G., Ferre, R., Planas, M., Feliu, L., et al. (2010). Escherichia coli cell surface perturbation and disruption induced by antimicrobial peptides BP100 and pepR. J. Biol. Chem. 285, 27536-27544. doi: 10.1074/jbc.M110.130955

Bahar, A. A., and Ren, D. (2013). Antimicrobial peptides. Pharmaceuticals 6, 1543-1575. doi: 10.3390/ph6121543

Bahnsen, J. S., Franzyk, H., Sandberg-Schaal, A., and Nielsen, H. M. (2013). Antimicrobial and cell-penetrating properties of penetratin analogs: effect of sequence and secondary structure. Biochim. Biophys. Acta 1828, 223-232. doi: 10.1016/j.bbamem.2012.10.010

Baltzer, S. A., and Brown, M. H. (2011). Antimicrobial peptides-promising alternatives to conventional antibiotics. J. Mol. Microbiol. Biotechnol. 20, 228-235. doi: 10.1159/000331009

Barbosa, M., Vale, N., Costa, F. M. T. A., Martins, M. C. L., and Gomes, P. (2017). Tethering antimicrobial peptides onto chitosan: optimization of azide-alkyne "click" reaction conditions. Carbohydr. Polym. 165, 384-393. doi: 10.1016/j. carbpol.2017.02.050

Barry, A. L., Craig, W. A., Nadler, H., Reller, L. B., Sanders, C. C., and Swenson, J. M. (1999). Methods for Determining Bactericidal Activity of Antimicrobial Agents; Approved Guidelines. Wayne, PA: Clinical and Laboratory Standards Institute (CLSI).

Beveridge, T. J. (1999). Structures of gram-negative cell walls and their derived membrane vesicles. J. Bacteriol. 181, 4725-4733.

Bobone, S., Piazzon, A., Orioni, B., Pedersen, J. Z., Nan, Y. H., Hahm, K. S., et al. (2011). The thin line between cell-penetrating and antimicrobial peptides: the case of Pep-1 and Pep-1-K. J. Pept. Sci. 17, 335-341. doi: 10.1002/psc.1340

Brogden, K. A. (2005). Antimicrobial peptides: pore formers or metabolic inhibitors in bacteria? Nat. Rev. Microbiol. 3, 238-250. doi: 10.1038/ nrmicro1098
Skłodowska-Curie Research and Innovation Staff Exchange (RISE): call H2020-MSCA-RISE-2014, Grant agreement 644167, 2015-2019. SD, JF, and DG acknowledge FCT for fellowships PD/BD/114425/2016, SFRH/BD/70423/2010, and SFRH/BPD/109010/2015, respectively, and MD for a grant (PTDC/BBB-BQB/3494/2014). ASV and NV acknowledge FCT for funding within the FCT Investigator Programme, IF/00803/2012 and IF/00092/2014, respectively. CP-P acknowledges financial support from the Spanish Ministry of Economy and Competitiveness, through grant AGL2014-52395C2-2-R and the "María de Maeztu" Programme for Units of Excellence in R\&D (MDM-2014-0370). PG acknowledges "Comissão de Coordenação e Desenvolvimento Regional do Norte (CCDR-N)/NORTE2020/Portugal 2020" for funding through project DESignBIOtechHealth (ref. Norte-01-0145FEDER-000024). SH is the recipient of an Australian Research Council Future Fellowship (FT150100398).

\section{ACKNOWLEDGMENT}

The authors thank Tiago Figueira for the help with data analysis.

\section{SUPPLEMENTARY MATERIAL}

The Supplementary Material for this article can be found online at: http://journal.frontiersin.org/article/10.3389/fmicb. 2017.00775/full\#supplementary-material

Brogden, N. K., and Brogden, K. A. (2011). Will new generations of modified antimicrobial peptides improve their potential as pharmaceuticals? Int. J. Antimicrob. Agents 38, 217-225. doi: 10.1016/j.ijantimicag.2011.05.004

Brown, D. (2015). Antibiotic resistance breakers: Can repurposed drugs fill the antibiotic discovery void? Nat. Rev. Drug Discov. 14, 821-832. doi: 10.1038/ $\operatorname{nrd} 4675$

Bulet, P., Stöcklin, R., and Menin, L. (2004). Anti-microbial peptides: from invertebrates to vertebrates. Immunol. Rev. 198, 169-184. doi: 10.1111/j.01052896.2004.0124.x

Chen, H. L., Su, P., Chang, Y., Wu, S., Liao, Y., Yu, H., et al. (2013). Identification of a novel antimicrobial peptide from human hepatitis $\mathrm{B}$ virus core protein arginine-rich domain (ARD). PLoS Pathog. 9:e1003425. doi: 10.1371/journal. ppat. 1003425

Clement, S., Vaudaux, P., Francois, P., Schrenzel, J., Huggler, E., Kampf, S., et al. (2005). Evidence of an intracellular reservoir in the nasal mucosa of patients with recurrent Staphylococcus aureus rhinosinusitis. J. Infect. Dis. 192, 1023-1028. doi: 10.1086/432735

Domingues, M. M., Castanho, M. A. R. B., and Santos, N. C. (2009). rBPI21 promotes lipopolysaccharide aggregation and exerts its antimicrobial effects by (hemi)fusion of PG-containing membranes. PLoS ONE 4:e8385. doi: 10.1371/ journal.pone.0008385

Ernst, R. K., Guina, T., and Miller, S. I. (1999). How intracellular bacteria survive: surface modifications that promote resistance to host innate immune responses. J. Infect. Dis. 179, S326-S330. doi: 10.1086/513850

Freire, J. M., Dias, S. A., Flores, L., Veiga, A. S., and Castanho, M. A. R. B. (2015a). Mining viral proteins for antimicrobial and cell-penetrating drug delivery peptides. Bioinformatics 31, 2252-2256. doi: 10.1093/bioinformatics/btv131

Freire, J. M., Santos, N. C., Veiga, A. S., Da Poian, A. T., and Castanho, M. A. R. B. (2015b). Rethinking the capsid proteins of enveloped viruses: multifunctionality from genome packaging to genome transfection. FEBS J. 282, 2267-2278. doi: $10.1111 /$ febs.13274 
Gautam, A., Chaudhary, K., Kumar, R., Sharma, A., Kapoor, P., Tyagi, A., et al. (2013). In silico approaches for designing highly effective cell penetrating peptides. J. Transl. Med. 11:74. doi: 10.1186/1479-5876-11-74

Gräslund, A., Madani, F., Lindberg, S., Langel, Ü, and Futaki, S. (2011). Mechanisms of cellular uptake of cell-penetrating peptides. J. Biophys. 2011:414729. doi: 10.1155/2011/414729

Hancock, R. E. W. (2001). Cationic peptides: effectors in innate immunity and novel antimicrobials. Lancet Infect. Dis. 1, 156-164. doi: 10.1016/S14733099(01)00092-5

Henriques, S. T., Melo, M. N., and Castanho, M. A. R. B. (2006). Cell-penetrating peptides and antimicrobial peptides: How different are they? Biochem. J. 399, 1-7. doi: 10.1042/BJ20061100

Jenssen, H., Hamill, P., and Hancock, R. E. W. (2006). Peptide antimicrobial agents. Clin. Microbiol. Rev. 19, 491-511. doi: 10.1128/CMR.00056-5

Kaplan, C. W., Sim, J. H., Shah, K. R., Kolesnikova-Kaplan, A., Shi, W., and Eckert, R. (2011). Selective membrane disruption: mode of action of C16G2, a specifically targeted antimicrobial peptide. Antimicrob. Agents Chemother. 55, 3446-3452. doi: 10.1128/AAC.00342-11

Levison, M. E., and Levison, J. H. (2009). Pharmacokinetics and pharmacodynamics of antibacterial agents. Infect. Dis. Clin. North Am. 23, 791-819. doi: 10.1016/j.idc.2009.06.008.Pharmacokinetics

Mahlapuu, M., Håkansson, J., Ringstad, L., and Björn, C. (2016). Antimicrobial peptides: an emerging category of therapeutic agents. Front. Cell. Infect. Microbiol. 6:194. doi: 10.3389/fcimb.2016.00194

Melo, M., Ferre, R., and Castanho, M. (2009). Antimicrobial peptides: linking partition, activity and high membrane-bound concentrations. Nat. Rev. Microbiol. 7, 245-250. doi: 10.1038/nrmicro2095

Melo, M. N., and Castanho, M. A. R. B. (2007). Omiganan interaction with bacterial membranes and cell wall models. Assigning a biological role to saturation. Biochim. Biophys. Acta 1768, 1277-1290. doi: 10.1016/j.bbamem.2007.02.005

Mileykovskaya, E., and Dowhan, W. (2000). Visualization of phospholipid domains in Escherichia coli by using the cardiolipin-specific fluorescent dye $10-N$-nonyl acridine orange. J Bacteriol 182, 1172-1175. doi: 10.1128/JB.182.4.1172-1175. 2000

Mogi, T., and Kita, K. (2009). Gramicidin S and polymyxins: the revival of cationic cyclic peptide antibiotics. Cell. Mol. Life Sci. 66, 3821-3826. doi: 10.1007/ s00018-009-0129-9

Monteiro, C., Fernandes, M., Pinheiro, M., Maia, S., Seabra, C. L., FerreiraDa-Silva, F., et al. (2015). Antimicrobial properties of membrane-active dodecapeptides derived from MSI-78. Biochim. Biophys. Acta 1848, 1139-1146. doi: 10.1016/j.bbamem.2015.02.001

Nekhotiaeva, N., Elmquist, A., Rajarao, G. K., Hällbrink, M., Langel, U., and Good, L. (2004). Cell entry and antimicrobial properties of eukaryotic cellpenetrating peptides. FASEB J. 18, 394-396. doi: 10.1096/fj.03-0449fje

Nguyen, L. T., Haney, E. F., and Vogel, H. J. (2011). The expanding scope of antimicrobial peptide structures and their modes of action. Trends Biotechnol. 29, 464-472. doi: 10.1016/j.tibtech.2011.05.001

Park, C. B., Yi, K. S., Matsuzaki, K., Kim, M. S., and Kim, S. C. (2000). Structureactivity analysis of buforin II, a histone $\mathrm{H} 2 \mathrm{~A}$-derived antimicrobial peptide: the proline hinge is responsible for the cell-penetrating ability of buforin II. PNAS 97, 8245-8250. doi: 10.1073/pnas.150518097

Peters, B. M., Shirtliff, M. E., and Jabra-Rizk, M. A. (2010). Antimicrobial peptides: Primeval molecules or future drugs? PLoS Pathog. 6:e1001067. doi: 10.1371/ journal.ppat.1001067

Piers, K. L., Brown, M. H., and Hancock, R. E. W. (1994). Improvement of outer membrane-permeabilizing and lipopolysaccharide-binding activities of an antimicrobial cationic peptide by C-terminal modification. Antimicrob. Agents Chemother. 38, 2311-2316. doi: 10.1128/AAC.38.10.2311

Powers, J. P. S., and Hancock, R. E. W. (2003). The relationship between peptide structure and antibacterial activity. Peptides 24, 1681-1691. doi: 10.1016/j. peptides.2003.08.023

Roth, B. L., Poot, M., Yue, S. T., and Millard, P. J. (1997). Bacterial viability and antibiotic susceptibility testing with SYTOX green nucleic acid stain. Appl. Environ. Microbiol. 63, 2421-2431.

Rozek, A., Powers, J. P. S., Friedrich, C. L., and Hancock, R. E. W. (2003). Structure-based design of an indolicidin peptide analogue with increased protease stability. Biochemistry 42, 14130-14138. doi: 10.1021/bi035643g

Sancho-Vaello, E., and Zeth, K. (2015). Antimicrobial peptides: Has their time arrived? Future Microbiol. 10, 1103-1106. doi: 10.2217/fmb.15.45
Sandri, A. M., Landersdorfer, C. B., Jacob, J., Boniatti, M. M., Dalarosa, M. G., Falci, D. R., et al. (2013). Pharmacokinetics of polymyxin B in patients on continuous venovenous haemodialysis. J. Antimicrob. Chemother. 68, 674-677. doi: $10.1093 / \mathrm{jac} / \mathrm{dks} 437$

Sani, M. A., Henriques, S. T., Weber, D., and Separovic, F. (2015). Bacteria may cope differently from similar membrane damage caused by the Australian tree frog antimicrobial peptide maculatin 1.1. J. Biol. Chem. 290, 19853-19862. doi: 10.1074/jbc.M115.643262

Shai, Y. (2002). Mode of action of membrane active antimicrobial peptides. Biopolymers 66, 236-248. doi: 10.1002/bip.10260

Splith, K., and Neundorf, I. (2011). Antimicrobial peptides with cell-penetrating peptide properties and vice versa. Eur. Biophys. J. 40, 387-397. doi: 10.1007/ s00249-011-0682-7

Takeshima, K., Chikushi, A., Lee, K. K., Yonehara, S., and Matsuzaki, K. (2003). Translocation of analogues of the antimicrobial peptides magainin and buforin across human cell membranes. J. Biol. Chem. 278, 1310-1315. doi: 10.1074/jbc. M208762200

Tanwar, J., Das, S., Fatima, Z., and Hameed, S. (2014). Multidrug resistance: an emerging crisis. Interdiscip. Perspect. Infect. Dis. 2014:541340. doi: 10.1155/ $2014 / 541340$

Teixeira, V., Feio, M. J., and Bastos, M. (2012). Role of lipids in the interaction of antimicrobial peptides with membranes. Prog. Lipid Res. 51, 149-177. doi: 10.1016/j.plipres.2011.12.005

Torcato, I. M., Huang, Y. H., Franquelim, H. G., Gaspar, D. D., Craik, D. J., Castanho, M. A. R. B., et al. (2013). The antimicrobial activity of sub3 is dependent on membrane binding and cell-penetrating ability. Chembiochem 14, 2013-2022. doi: 10.1002/cbic.201300274

Torrent, M., Di Tommaso, P., Pulido, D., Nogués, M. V., Notredame, C., Boix, E., et al. (2012). AMPA: an automated web server for prediction of protein antimicrobial regions. Bioinformatics 28, 130-131. doi: 10.1093/bioinformatics/ btr604

Ventola, C. L. (2015). The antibiotic resistance crisis: part 1: causes and threats. P T 40, 277-283.

WHO (2014). Antimicrobial Resistance: Global Report on Surveillance, Vol. 61. Geneva: World Health Organization, 383-394. doi: 10.1007/s13312-0140374-3

Wiegand, I., Hilpert, K., and Hancock, R. E. W. (2008). Agar and broth dilution methods to determine the minimal inhibitory concentration (MIC) of antimicrobial substances. Nat. Protoc. 3, 163-175. doi: 10.1038/nprot.2007.521

Wikler, M. A., Low, D. E., Cockerill, F. R., Sheehan, D. J., Craig, W. A., Tenover, F. C., et al. (2006). Methods for Dilution Antimicrobial Susceptibility Tests for Bacteria that Grow Aerobically: Approved Standard. Wayne, PA: Clinical and Laboratory Standards Institute (CLSI).

Wu, M., and Hancock, R. E. W. (1999). Improved derivatives of bactenecin, a cyclic dodecameric antimicrobial cationic peptide. Antimicrob. Agents Chemother. 43, 1274-1276.

Xia, G., Kohler, T., and Peschel, A. (2010). The wall teichoic acid and lipoteichoic acid polymers of Staphylococcus aureus. Int. J. Med. Microbiol. 300, 148-154. doi: 10.1016/j.ijmm.2009.10.001

Yeaman, M. R., and Yount, N. Y. (2003). Mechanisms of antimicrobial peptide action and resistance. Pharmacol. Rev. 55, 27-55. doi: 10.1124/pr.55.1.2

Zasloff, M. (2002). Antimicrobial peptides of multicellular organisms. Nature 415, 389-395.

Zhu, W. L., Lan, H., Park, I. S., Kim, J. II, Jin, H. Z., Hahm, K. S., et al. (2006). Design and mechanism of action of a novel bacteria-selective antimicrobial peptide from the cell-penetrating peptide Pep-1. Biochem. Biophys. Res. Commun. 349, 769-774. doi: 10.1016/j.bbrc.2006.08.094

Conflict of Interest Statement: The authors declare that the research was conducted in the absence of any commercial or financial relationships that could be construed as a potential conflict of interest.

Copyright (c) 2017 Dias, Freire, Pérez-Peinado, Domingues, Gaspar, Vale, Gomes, Andreu, Henriques, Castanho and Veiga. This is an open-access article distributed under the terms of the Creative Commons Attribution License (CC BY). The use, distribution or reproduction in other forums is permitted, provided the original author(s) or licensor are credited and that the original publication in this journal is cited, in accordance with accepted academic practice. No use, distribution or reproduction is permitted which does not comply with these terms. 